REPORT OF

A SEVERE LACERATED WOUND OF THE FACE AND SCALP, LIGATURE OF THE COMMON CAROTID ARTERY, AND RECOVERY.

BT S. T. CHADWICK, M.D. Edin., M.R.C.S. \&c. Lond., Bolton.

JOSEPH B-, aged thirteen years, who resided in Foundrystreet, Bolton, and assisted his father at the trade of a woodturner, was engaged, one afternoon, in that occupation, when, in consequence of his foot slipping, he fell upon a circular saw, of about twenty inches in diameter, which inflicted a severe wound, extending from the anterior border of the masseter muscle, passing along the ramus and angle of the inferior maxilla, across the neck, a little below the mastoid process of the temporal bone, to the superior transverse ridge of the occipital bone, and terminating near the protuberance of that bone. He was carried to my surgery by two men, bleeding profusely, and in a state of great exhaustion.

The injury was on the right side of the neck and face; the wound was very deep; the edges were uneven, and jagged by the teeth of the saw; the muscles were considerably lacerated; and several branches of the external carotid artery were cut across. The occipital bone was deeply grooved for more than two inches in extent. The hæmorrhage, which was very profuse, was not arrested before the application of about six ligatures. After cleaning the wound, which contained a quantity of hair, and several spicula of bone, the edges were brought partially into apposition with adhesive plaster, light dressings and bandages were applied, and the boy was conveyed home in a cab, a distance short of half a mile.

I visited him early on the following morning, and found him greatly agitated. His mother informed me that he had passed a restless night-not so much from pain resulting from the wound, as excitement and alarm. I directed him to be kept quiet, a dose of castor oil to be administered, and his regimen to be lightly antiphlogistic. In the evening, owing to the agitation continuing, I prescribed a pill of calomel, opinm, and tartar-emetic.

On the third day he was reported to have had some sound sleep, and his appearance was certainly more tranquil, although the pulse was quick, the skin dry and hot, tongue furred, and he complained of slight pain in the head. The oil had operated twice, freely. He complained of the wound feeling stiff and measy. There had been no further bleeding since the first dressing.

On the fourth day there was less febrile disposition, but the integuments near the wound were swollen, red, and painful; a slight erysipelatous blush was extending over that side of the neck and face. I removed the bandages and dressings. The surface of the wound had a livid appearance, and was covered with an ichorous, foetid discharge. Simple dressing was applied, and a bread-and-water poultice. The citrate of potash, with small doses of the antimonial solution, were administered every four or six hours. As he complained of the weight of the poultice, an evaporating lotion was substituted, the effect of which (as he expressed himselfi) was very grateful.

On the succeeding day the fever was more abated, the parts near the injury were considerably less swollen, the pain had subsided, the redness about the neck and face was not so extensive, and his condition altogether was much more favourable. For the four following days the case progressed quite satisfactorily.

On the eighth day $I$ again dressed the wound, which had put on a much cleaner and more healthy appearance, granulations shooting up in different parts, and covered with healthy pus.

In about four hours after I had left him, a messenger came to my surgery, in great haste, to say that the boy was bleeding to death. I immediately repaired to the house, where I found him, supported by two females, almost insensible, and completely blanched, a lake of blood surrounding his neck and chest, of an arterial character; the breathing anxious and hurried; the extremities covered with a cold, clammy perspiration; the pulse almost imperceptible.

I immediately opened the wound, but in consequence of the syncope the bleeding had ceased. However, as soon as reaction commenced, I observed bleeding from two or three points. I employed both tenaculum and forceps to secure the bleeding orifices; but owing to the condition of the wound, unless I included a considerable portion of surrounding structure, the instrument did not retain its hold; and even then, on applying the ligature, it cut itself out.
It was evident that any further hæemorrhage could not be borne with impunity; therefore I determined, without further delay, to cut down on, and place a ligature around, the common carotid. From the exhausted state of the patient, and not having an assistant, the operation was rather protracted.

Owing to the great loss of blood, the boy continued in a weak and precarious condition for several days; after which he began to rally and gain strength rapidly, his appetite returned, no further hæmorrhage occurred, and in a month he was able to come down stairs. The wound put on a florid, heal thy appearance, and in about seven or eight weeks it was completely cicatrized, excepting at one point, where there was a small exfoliation from the cranium. The ligature left the carotid about the twenty-fourth day.

He had no cerebral disturbance after the operation; indeed, not one unfavourable symptom was manifest.

On account of the great extent of the wound, (more than seven inches,) and its locality, the application of pressure was impracticable; and I consider that any delay in so urgent a case would have been highly culpable.

An unseemly scar exists on the side of the neck and face, and permanent baldness over the place of injury to the scalp. Bolton, Lancashire, 1850.

\section{ON A CASE OF APPROACH TO THE SURFACE OF THE BODY OF SUBSTANCES FORMERLY SWALLOWED.}

Bx JOHN WINZAR, Esq., M.R.C.S. \&c., Salisbury. IT is perhaps twenty-seven years ago since my late father, who was in attendance on a lady in this neighbourhood, (suffering from mental aberration, had his attention directed by the nurse to examine the lower part of his patient's abdomen, pain having been felt in that locality a few days previously. On pressure, he found a hard oviform substance underneath the skin; by the free ase of his common bleeding lancet he cut down to it, and extracted from the opening thus made a silver teaspoon, of the usual length, (about five inches.) This was soon followed by three or four pieces of whalebone, of similar length, and a piece of red cloth, all of which had a few months previously been swallowed, during a period of more than usual maniacal violence.

The patient speedily recovered the little constitutional irritation thus set up, and reparation of surface was soon effected. The spoon is now in my possession, and some of the whalebones, though mutilated; the piece of cloth has been lost some time.

Some members of the family in this neighbourhood will confirm this statement, if requisite.

Salisbury, Jan. 29, 1851

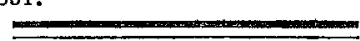

\section{A mírror \\ OF THE PRACTICE OF

MEDICINE AND SURGERY
HOSPITALS OF LONDON.

Nulla est alia pro certo noscendi via, nisi quam plurimas et morborum, et dissectionum historias, tum aliorum proprias, collectas habere et inter se comparare.-MoraAgNI. De Sed. et Caus. MIorb., lib. 14. Procmium.

\section{GUY'S HOSPITAL.}

Rheumatic Fever treated by A cetate of Potash.

(Under the care of Dr. Golding Brad.)

ONE of the acute diseases which the hospital physician is most frequently called upon to treat is rheumatic fever; we have ample opportunities of seeing this fact verified, and have taken advantage of that circumstance to observe the methods of treatment which are employed in the hospitals of London against this very common affection. If our readers will refer to the following numbers of THE LANCET:-March 9, 1850, p. 307; August 24, 1850, p. 243; November 16, 1850, p. 541; they will find acute rheumatism treated with colchicum, acetate and nitrate of potash, and lemon-juice respectively. We now beg their attention for a few moments, whilst we give an outline of Dr. Golding Bird's treatment of rheumatic fever with acetate of potash alone. It is of course understood that the generality of physicians abstract blood, either generally or locally, 